\title{
Experiences, expectations and challenges of an interactive mobile phone-based system to support self-management of hypertension: patients' and professionals' perspectives
}

This article was published in the following Dove Press journal:

Patient Preference and Adherence

\author{
Inger Hallberg'-3 \\ Agneta Ranerup ${ }^{3,4}$ \\ Ulrika Bengtsson 1,3 \\ Karin Kjellgren ${ }^{1-3}$ \\ 'Institute of Health and Care \\ Sciences, University of Gothenburg, \\ Gothenburg, Sweden; ${ }^{2}$ Department \\ of Medical and Health Sciences, \\ Linköping University, Linköping, \\ Sweden; ${ }^{3}$ Centre for Person- \\ Centred Care (GPCC), University of \\ Gothenburg, Gothenburg, Sweden; \\ ${ }^{4}$ Department of Applied Information \\ Technology, University of Gothenburg, \\ Gothenburg, Sweden
}

\begin{abstract}
Background: A well-controlled blood pressure (BP) reduces cardiovascular complications. Patient participation in care using technology may improve the current situation of only $13.8 \%$ of adults diagnosed with hypertension worldwide having their BP under control.

Objective: The objective of this study was to explore patients' and professionals' experiences of and expectations for an interactive mobile phone-based system to support self-management of hypertension.
\end{abstract}

Methods: The self-management system consists of: 1) a mobile phone platform for self-reports, motivational messages and reminders; 2) a device for measuring BP and 3) graphical feedback of self-reports. Patients diagnosed with high BP $(n=20)$ and their treating professionals $(n=7)$ participated in semi-structured interviews, after 8 weeks use of the system in clinical practice. Data were analyzed thematically.

Results: The self-reporting of BP, symptoms, medication use, medication side effects, lifestyle and well-being was perceived to offer insight into how daily life activities influenced BP and helped motivate a healthy lifestyle. Taking increased responsibility as a patient, by understanding factors affecting one's well-being, was reported as an enabling factor for a more effective care. Based on the experiences, some challenges were mentioned: for adoption of the system into clinical practice, professionals' educational role should be extended and there should be a reorganization of care to fully benefit from technology. The patients and professionals gave examples of further improvements to the system, for example, related to the visualization of graphs from self-reports and an integration of the system into the general technical infrastructure. These challenges are important on the path to accomplishing adoption.

Conclusion: The potential of a more autonomous, knowledgeable and active patient, through use of the interactive mobile system would improve outcomes of hypertension treatment, which has been desired for decades. Documentation and visualization of patients' self-reports and the possibilities to communicate these with professionals may be a significant resource for person-centered care.

Keywords: adherence, adoption, blood pressure, cellular phone, mHealth, person-centered care

\section{Introduction}

A well-controlled blood pressure (BP) is essential for reducing the burden of complications associated with high $\mathrm{BP},{ }^{1}$ such as coronary artery disease, congestive heart failure, stroke and chronic kidney disease. ${ }^{2}$ However, only $\sim 13.8 \%$ of people diagnosed with hypertension worldwide have their BP under control. ${ }^{3}$ 
The role of a patient in hypertension care is to adhere to and actively participate in treatment, make evidence-based lifestyle choices and manage the symptoms that occur. ${ }^{4}$ There is a great variation in revisit intervals for hypertension followups, ${ }^{5}$ often leaving the patient uncertain as to their BP level, BP targets and how these relate to daily life activities. The possibility to follow, for example, the potential influence of physical activity, stress and sleep on BP can offer opportunities to improve patient outcomes. Self-management of chronic illness refers to actions taken by a patient to manage his or her health problem, with support from a health care professional. ${ }^{6,7}$ The approach of self-management conducted within the frame of a patient-professional relationship is in line with person-centeredness, ${ }^{8}$ which in our context would account for a well-informed, knowledgeable and active patient who is aware of the importance of reaching BP targets. ${ }^{9}$

A recent review ${ }^{10}$ showed that self-management of hypertension using technology improved BP control and the importance to involve both patients and professionals. However, there are many barriers that may prevent or slow the adoption of new therapeutic advances supported by health information technology into routine clinical practice. ${ }^{11}$ Therefore, better systems of care should be developed that improve and sustain long-term commitment to prescriptions. ${ }^{12}$ Adoption depends on understanding patients' and professionals' experiences and expectations regarding technology use. Research focusing on such experiences often assesses patients' or professionals' experiences separately. Recent examples include Langenau et $\mathrm{a}^{13}$ studying physicians' use of Skype in communicating with patients and Ketikidis et a ${ }^{14}$ examining the acceptance of information technology by health professionals in general, including nurses and physicians. In contrast, Rosas et al ${ }^{15}$ and Mulvaney et $\mathrm{al}^{16}$ are two studies focusing on patients' experiences of health information technology with a more explicit self-management agenda. However, to attain wellchosen strategies for adoption and appropriation in regular care, empirical studies that include both strategic groups and relevant empirical contexts are to be preferred. One of the few studies with this approach is Antheunis et al, ${ }^{17}$ which examined the motives, barriers and expectations of patients and health care professionals involving social media use. Bengtsson et $\mathrm{al},{ }^{18}$ in turn, studied patient and professional perspectives on hypertension treatment for use in the development of a mobile phone-based platform. These studies found similarities and differences in motives for technology use and preferred technologies. More importantly, there were differences between the groups regarding the perception of patients' expectations and capacities. In sum, it is essential that intervention strategies focus on improving the adoption of new therapies and technologies into clinical practice, not to simply aim to create episodic, but rather long-term, engagement by users. ${ }^{19}$

This study is part of a research program aiming to develop and evaluate an interactive mobile phone-based system for supporting the self-management of hypertension from a person-centered perspective. ${ }^{20}$ Person-centeredness ${ }^{8}$ emphasizes the value of the patient's own experiences of their situation and is an important perspective in the program. Therefore, the following ideals are important: 1) partnership and participation, taking into account patient views; 2) patient reports, for example through the use of BP self-measurement technology and 3) the documentation of patient reports in the mobile phone being part of the system. The system comprises a set of questions and motivational messages delivered and captured by means of mobile phone-based technology. After patients and professionals had used this self-management support system in hypertension care for 8 weeks, we aimed to explore their views regarding their experiences and expectations to improve the possibilities for adoption in clinical practice. This paper is a secondary analysis of a cohort study of a mobile phone-based self-management support system for patients with hypertension. We have earlier reported patients' experiences of the system with a specific focus on perceived more direct utility and insights. ${ }^{21}$ Together with a subgroup of the patients included in the earlier study, in this study, we also include professionals to explore the future expectations and challenges that influence the possibilities to implement the system in clinical practice. Therefore, this paper is based on interviews with both patients and professionals about their experiences of and expectations for using a self-management system in daily life as well as in clinical contexts, which are essential for achieving such a purpose.

\section{Methods}

\section{Study setting and participants}

\section{Patients}

Participants in this study were recruited from the sample of 50 patients in the 8-week intervention study. ${ }^{21} \mathrm{~A}$ convenient sample was used. Thus, 20 patients from four primary health care centers who agreed to participate in the 8-week study were consecutively asked by their nurse or physician to participate in the present study. The inclusion criteria were as follows: 1) able to understand and speak Swedish; 2) >30 years of age and 3) currently taking medication for hypertension. To retrieve knowledge from experienced patients with hypertension, patients $>30$ years of age were included. The 20 patients were interviewed by IH and UB immediately after their ordinary follow-up consultation with their nurse or physician. Patient characteristics are shown in Table 1. 


\section{Table I Patient characteristics}

\begin{tabular}{|c|c|}
\hline \multicolumn{2}{|l|}{ Patients ( $n=20)$} \\
\hline Females, n (\%) & II (55) \\
\hline Age mean (range) & $56(43-72)$ \\
\hline Systolic BP (mmHg), mean (range) ${ }^{\mathrm{a}}$ & $139(120-169)$ \\
\hline Diastolic BP (mmHg), mean (range) ${ }^{a}$ & $83(7 \mid-100)$ \\
\hline Years with hypertension, mean (range) & $6.8(<\mathrm{I}-25)$ \\
\hline \multicolumn{2}{|l|}{ Marital status, $\mathrm{n}(\%)$} \\
\hline Married & $14(70)$ \\
\hline Unmarried & $6(30)$ \\
\hline \multicolumn{2}{|l|}{ Education, n (\%) } \\
\hline Compulsory school ( $\leq 9$ years) & $2(10)$ \\
\hline High school (9-12 years) & $8(40)$ \\
\hline University & $10(50)$ \\
\hline \multicolumn{2}{|l|}{ Employment status, n (\%) } \\
\hline Employed & II (55) \\
\hline Retired & $9(45)$ \\
\hline
\end{tabular}

Note: ${ }^{\text {AAt inclusion. }}$

Abbreviation: BP, blood pressure.

\section{Health care professionals}

The professionals $(n=7)$ who conducted and agreed to participate in the follow-up consultations after use of the system were all females aged 33-65 years and consisted of six nurses and one physician. A convenient sample was used, and the health care professionals who had a scheduled appointment with the patient for follow-up after use of the system participated. All were experienced in hypertension care (range 3-22 years), and four of the nurses had specialist training in public health/primary care.

\section{Intervention}

The interactive mobile phone-based self-management support system (referred to as the system) consists of three main components: 1) a mobile phone platform for the delivery and capture of patient reports of well-being, symptoms, lifestyle, medication intake, side effects, BP, tailored phonebased motivational messages and reminders; 2) a device for measuring BP and 3) a web-based feedback system showing graphs of the self-reported data. To be found elsewhere are detailed descriptions of the design, development and validation process, $;^{18,20,22,23}$ the patients' more immediate experiences of using the technology ${ }^{21}$ and an analysis of the effect of BP after 8 weeks of using the self-management system. ${ }^{24}$

The communication platform for the delivery of the system was developed by 21 st Century Mobile AB (Stockholm, Sweden) (www.cqmobil.se) ${ }^{42}$ and was designed to allow daily self-reports to be registered by means of the patients' own mobile phones and then returned to and stored in a secure database.

At the start-up meeting, patients were trained in measuring their BP, according to the European Society of Hypertension Practice Guidelines for home blood pressure monitoring. ${ }^{25}$ A home blood pressure monitor (BP A200 AFIB; Microlife USA Inc., Clearwater, FL, USA), validated according to the international protocol of the European Society of Hypertension, was used. ${ }^{26}$ The study intervention is briefly summarized in Figure 1.

\section{Data collection}

Source data consisted of $16 \mathrm{~h}$ and $49 \mathrm{~min}$ of audio-recorded face-to-face interviews, held with 20 patients and their treating professionals immediately after the follow-up consultations after 8 weeks use of the system.

A semi-structured interview guide with open-ended questions about experiences from and expectations for using the system in daily life (home context) as well as experiences from the follow-up consultation (clinical context) was used. Examples of interview questions to both patients and professionals were: What are your experiences from participating in the project?, What was your understanding of the graphs?

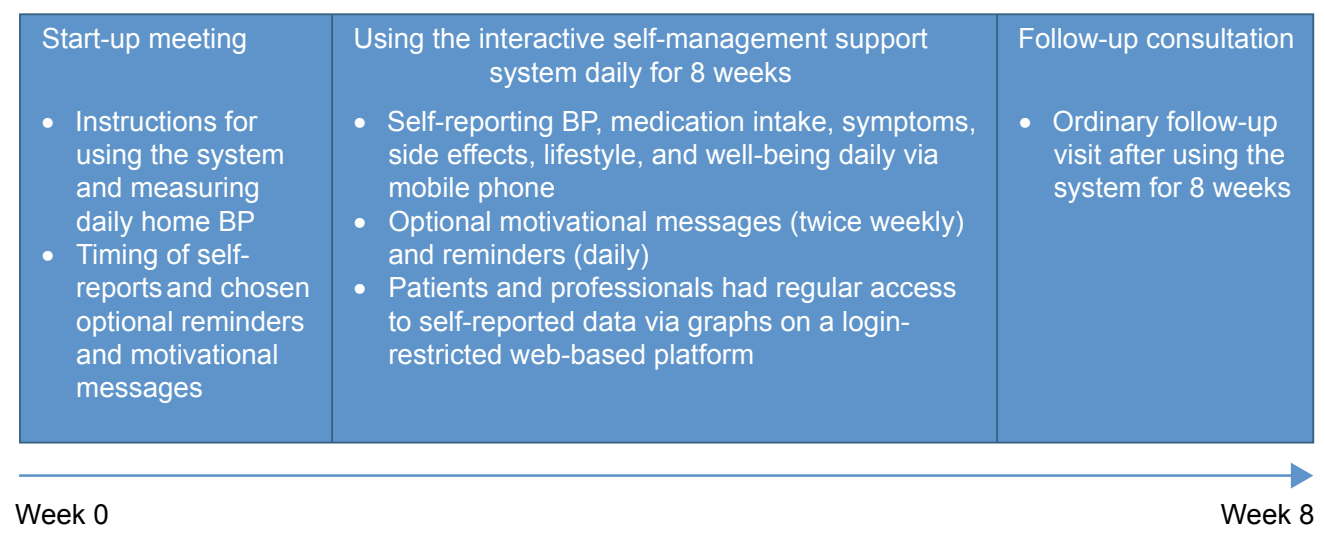

Figure I Overview of the study intervention.

Abbreviation: BP, blood pressure. 
and How would you describe today's follow-up consultation compared to "the usual follow-up" consultations in hypertension care? Professionals were asked their views of the self-management system and how it affected practice or management (if at all), for example: How was the system of value and relevant to your communication with patients? Interviewers asked probing questions to clarify, deepen and develop the responses. Data were collected from April 2012 to June 2012.

\section{Data analysis}

The interviews were transcribed verbatim and were coded using NVivo 10 (QSR International Pte Ltd., Doncaster, VIC, Australia). Qualitative thematic analysis was used to analyze the data and was chosen as an appropriate method for identifying, analyzing, interpreting and reporting themes. ${ }^{27}$ The analysis focused on themes addressed in the interviews regarding patients' and professionals' views of opportunities and barriers posed by the system.

We developed a coding framework to organize the data systematically based on analyses of the transcripts. When searching for themes, we considered how they could be combined into subthemes from which overarching themes could be derived. We reviewed the suggested themes to determine whether they worked in relation to our codes and whether they were valid in relation to the entire data set, by reading all assembled quotes for each theme. To present and visualize the results, illustrative quotes were identified. The analysis was iterative and was performed by the first author in collaboration with the co-authors, which we then discussed in order to reach agreement in our understanding of the data; furthermore, the interpretation was supported by several multidisciplinary discussions within the research program.

\section{Ethical considerations}

The study, approved by the regional ethics board in Gothenburg, Sweden (study codes 551-09 and T-100-12), was conducted in accordance with the Declaration of Helsinki. ${ }^{28}$ All patients were informed about the study, both in writing and verbally, by their health care professional and the researchers before they gave written informed consent. Transcripts were anonymized, and the patients were assured confidentiality. The study was registered in the Clinical Trial Protocol Registration System (ClinicalTrials.gov NCT01510301), under the acronym MIHM (Mobile phone In Hypertension Management), and was further monitored by an independent monitoring board.

\section{Results}

The analysis resulted in three themes (displayed in Table 2): experiences after use of the system, expectations after use of the system and challenges for adoption in hypertension care and underlying subthemes.

\section{Experiences after use of the system Contributing to understanding, insight and motivation}

Professionals and patients were generally positive about the system. They also perceived that it was a user-friendly tool. Patients said that they had previously not known what was regarded as normal BP levels. They felt they had received confirmation of the interplay between BP and other selfreported data and that they had recognized the importance of a better lifestyle. They also emphasized that the system could be of help to professionals in increasing their knowledge and understanding of how patients felt:

The positive thing was that the staff got better insight into how the relations were connected, and could therefore conduct a better analysis [...] Lying on a stretcher twice a year and having your blood pressure checked, that's not the same thing. [Male Patient (Pt) 12]

The professionals believed that the system had generally worked well for the patients. From their own perspective, they experienced it as relevant and usable. Through the system, they had increased their insight into the patients' thoughts and perceptions about their condition:

I've gone in and checked multiple times every week, because I have a [patient] who's made an adjustment to his medication. This has been a really good tool for checking what happened with his blood pressure. He also suffered from headaches, among other things, so I was able to follow his well-being and see how it improved. [Professional 5]

Table 2 Overview of the subthemes and overarching themes

\begin{tabular}{ll}
\hline Subthemes & Themes \\
\hline $\begin{array}{l}\text { Contributing to understanding, insight and } \\
\text { motivation } \\
\text { Enabling new roles in care for patients and } \\
\text { professionals }\end{array}$ & $\begin{array}{l}\text { Experiences after use of } \\
\text { the system }\end{array}$ \\
$\begin{array}{l}\text { Becoming an accountable patient, based on } \\
\text { understanding }\end{array}$ & $\begin{array}{l}\text { Expectations after use } \\
\text { of the system }\end{array}$ \\
$\begin{array}{l}\text { Promoting a more efficient and effective care } \\
\text { Further need to develop the system } \\
\text { Redesign of care to benefit from new }\end{array}$ & $\begin{array}{l}\text { Challenges for adoption } \\
\text { technology }\end{array}$ \\
\hline
\end{tabular}




\section{Enabling new roles in care for patients and professionals}

The follow-up consultation was perceived as more substantial than previous, and it was noted that more patient-related issues were raised. The patients' experiences were in focus when the discussion was based on the graphs:

Now we have facts here [points to graphs] on how it looks, and it's every day, and how it varies from day to day. So it's a bit clearer to talk about it; with this information I myself have given, the visit's different and I have more information than I would otherwise be able to give, or remember, or have thought of. So it's good. [Female Pt 7]

The professionals experienced that the follow-up consultation changed in nature so that the patients could participate in a more informed way. They described a new situation in which facts about the "daily life" of the patient based on graphs were available both before and during the consultation.

Before, some people have simply taken the medicine because the doctor said to, without thinking any more about it; this is an "aha” moment I've had. This system has meant that I now dare to just ask straight out what they know about hypertension and what their reasoning is and how they take their medicine. [Professional 1]

The situation was new to the professionals in that the patients were prepared, which increased their insight into themselves and their illness, something that affected the consultation as such. Some professionals also felt that the focus of the consultation changed, with the self-reported data now at the center of attention.

\section{Expectations after use of the system \\ Becoming an accountable patient, based on understanding}

Patients saw advantages to the ability to measure and follow-up their BP, thereby being able to increase their responsibility for their own health in the future. This was confirmed by the professionals. Patients mentioned feeling safer when the professionals could follow their self-reported data. The patients also believed that the system increased their motivation to make lifestyle changes, as well as to maintain them. The professionals mentioned that the patients' new insight might lead to increased adherence to recommended treatment:

That the blood pressure reacts so differently and so quickly, and that you see that certain things are good for the pressure
- exercise, that's what I've seen the most [...] So this system has helped me; now I've seen it in black and white, so I'll keep that with me in the future. [Female Pt 14]

The professionals emphasized that their role had changed into that of a resource (a consultant) that could provide support when problems and questions arose for the patients:

I know she can do this [...] and she knows where to turn for help ... I'm here as a sounding board if things don't go well. [Professional 2]

\section{Promoting a more efficient and effective care}

The system was considered as very much in line with the current trend of increased focus on one's own health:

It's interesting that there's development, and that there are new methods that might be of help and continue building on various check-ups and care situations through technology.

[Professional 7]

Patients and professionals could see the potential future advantages to assuming responsibility for measuring and keeping track of variations in their BP. They felt that the system offered a flexible arrangement that also saved time, since the number of necessary follow-up consultations with the sole purpose of measuring their BP could be reduced. They believed that the system enabled closer contact with health care, through its capacity to submit data on BP and health issues. Both groups mentioned the potential value of the system when changes to medication are made, through its new capacity to monitor changes in BP and health "at a distance". The system also had value as a reminder to take one's medication:

I tell everybody they have to take control over their situation, to lose weight and increase exercise, and that this has resulted in improved health; then, you have to in some way be able to check this, and this system is just superb.

[Male Pt 18]

Professionals saw a potential for the system to improve the efficiency of care through its capacity to follow the patients' self-reported data and the related graphs "at a distance", which in turn can lead to a follow-up consultation over the phone rather than in person. This could make it easy to give patients feedback via the system and, on the other hand, to offer patients in need direct visits to their physician. Additionally, the professionals expressed that the system offered an overview of self-reported data that enabled insight into patients' daily life activities. They argued that 
in this way, it might serve as a link between the patient's home and the clinic:

I mean you can see it like you're moving the [health care] operations out and not meeting with the patient, but for some patients I think it feels good to take personal responsibility for their health $[\ldots]$ But for some it's easier to meet eye to eye. [Professional 4]

Furthermore, the professionals believed that in order to handle the system in a beneficial way, it was important for patients to be motivated and interested, not too old and possess some technical knowledge.

\section{Challenges for adoption in hypertension care}

\section{Further need to develop the system}

Both patients and professionals talked about the need to improve the graphs to make them easier to understand. A suggestion by the professionals was that the days of the week should be clearly displayed, so that variations in BP between workdays and weekends could be discussed. Another suggestion for a technical solution to improve the graphs was made by a patient:

you could perhaps also put in the [blood pressure] level you're normally supposed to have, a normal curve in a color [...] that's something I'd like to see, anyway, with the upper and lower blood pressure [...] like on the stock market [...] then you get a little food for thought and it tells you a bit more. [Male Pt 17]

Furthermore, both patients and professionals missed an opportunity to tailor the system according to personal preferences, for example to introduce new questions or adapt the schedule for self-reporting. Other suggestions involved a feature to comment on certain self-reported data, for example that reduced well-being might be caused by influenza, pain or other circumstances. Owing to the lack of this function, some patients made notes by hand in private, which became a resource in the conversation during the follow-up meeting. Sometimes the patients experienced technical problems when they started using the system, which in turn depended on differences in technical experience and the type of mobile phone they had. Patients requested clear information before starting to use the system, which should also be tailored to personal needs. Special focus should be on the issue of how to interpret the graphs of self-reported data.

\section{Redesign of care to benefit from new technology}

Different dimensions in the need to transform care were mentioned by patients and professionals when the former participated in their own care and assumed more responsibility. Professionals voiced feelings of uncertainty regarding the organization of the follow-up consultation in the new situation. The fact that patients expanded their role and activity in the consultation was perceived as largely positive, while others felt that the system as such was too much in focus during the follow-up conversation, implying that it interfered with the usual agenda.

For the patients, it became more obvious that they should assume responsibility for their BP values and raise issues related to this in the follow-up consultation. During the majority of the follow-up consultations, with only a few exceptions, patients' BP was not measured. A patient felt that measuring the BP was unnecessary, saying he had measured it himself on a daily basis for 8 weeks:

She [a staff member] asked how it had been and how the technology itself had worked, and looked at the diagram [...] how you can look between the different items to see, for example, if I'd had a bad night's sleep [...] and then perhaps my blood pressure was high. Yeah, then she rounded things off by taking my blood pressure [patient laughs a bit]. [Female Pt 1]

In cases in which professionals measured the BP during the follow-up visit, this was done to check whether it was consistent with the value measured by the patients at home. If the value was normal, this was used to make the patients feel calm and to assure them that everything was going well.

I was a bit surprised, because some of my patients have had lower measurements [of blood pressure] at the clinic than in the study, where they had higher measurements.

[Professional 5]

Professionals suggested that the system could be valuable for patients who might experience stress when their BP is measured in a clinical environment. On the other hand, it was said that the system might increase the levels of stress if BP is measured too frequently. This might also lead to an unnecessary increase in the diagnosis and treatment of hypertension.

Both patients and professionals mentioned the issue of lack of time. From the patients' perspective, this concerned not being able to log on to the computer and check the graphs in the way they wanted. Professionals cited the risk of there 
being a lack of time during follow-up visits if the visit took a bit longer than usual and the risk that there was no time for preparation on their side. In line with this, professionals brought up the issue that they did not have enough time to log on and check the values of patients' self-reported data. They also suggested that it would be useful to have reminders in case there were self-reported data that urgently needed to be viewed due to an extreme BP level, for example.

The professionals also raised an issue regarding the need for the system to be integrated into the general technical infrastructure in health care. This is of course related to partly technical and partly organizational issues.

\section{Discussion}

In concordance with our previous study, ${ }^{21}$ the patients appreciated the self-management system. Particularly, the interactive part of the mobile phone-based system was valued by the professionals. It gave insight into how daily life activities influenced BP and helped motivate a healthy lifestyle. The professionals also appreciated the system, especially the active role of the patients. However, they also expressed critical viewpoints, such as a lack of time as a limiting factor during as well as between patient encounters needing to be dealt with in a better way. Equally important are the challenges involved with the system being adopted in clinical practice: the expressed need to further develop the graphs, the educational role of professionals and the reorganization of care to fully benefit from the technology. As reported earlier, ${ }^{21}$ the interactive mobile phone-based system gave insights that increased motivation to follow the recommended treatment, ie, adherence, which also was obvious in this study.

The implementation of new systems must be done in an evidence-based way. To better fulfill the objective of hypertension care, an active involvement of patients has to be developed. ${ }^{10,29}$ However, self-management is a complex issue. In accordance with van de Bovenkamp and Dwarswaard, ${ }^{30}$ we argue that it relates to the norms and values of patients and professionals, as well as to underlying health care policies regarding the role of self-management in health care. Unrelated to the normative nature of the concept of self-management, it is important to study the more mundane aspects of how patients are able to handle their health problems with the support of new technology, along with support from professionals, as well as to take into account such practice-based experiences. ${ }^{31}$ In sum, we have studied a common chronic condition and believe that the results and design of the mobile phone-based platform, in collaboration with patients, can be transferred to other types of diagnoses with a potential for self-management.

Furthermore, a more detailed conclusion we can draw from this study is that the patients were eager to test, and saw several possibilities in using, the system. To be able to see relations between symptoms - for example, stress and well-being - as well as signs, BP and pulse were highly motivational for the patients. The way to visualize these relations was new to both patients and professionals. The patients became aware of their increased responsibility for their own health. However, the professionals often had a different, somewhat more critical, perspective. They met with several patients with hypertension and questioned how they could manage and meet to the expectations of the group of patients using the system. They focused more on details in the capacity of the system and issues of how their role and responsibility might change. Therefore, the new active role of the patients when they come to an appointment with their own self-reports gives rise to expectations for a well-prepared professional who has analyzed the collected data. To meet these experiences and challenges, the welldocumented agenda-driven structure of consultations ${ }^{32}$ has to be broken. As shown by Fletcher et al, ${ }^{33}$ self-monitoring of $\mathrm{BP}$ has the capacity to bridge a potential gap in the traditional patient-clinician relationship. The roles of patients and professionals have to be changed, and demanding activities related to a reorganization of care have to be performed. The system must be relevant and sustainable and add value to the clinical routines in a regular environment rather than simply being part of a pilot study. ${ }^{19}$ The importance of seamless hypertension care with a continuously well-controlled BP, knowledge ${ }^{34}$ not only at follow-up visits, will be possible with the "Quantified Self' health approach using mobile digital devices. ${ }^{35}$ In this manner, through our practical experiences, we contribute to a debate that views individuals either as capable and rational health care consumers through the means of technology or as victims of agendas related to an excessive ambition to save costs through self-management. ${ }^{31}$

The role of the patients thus has to change. A systematic review $^{33}$ concluded that the self-measurement of BP was successful in facilitating the interaction and bridging the gap in the patient-professional relationship, also reported by Flynn et al. ${ }^{36}$ Furthermore, a thematic synthesis regarding self-management support from the perspective of the patient emphasizes the importance of a relationship based on partnership. ${ }^{7}$ Both patients and professionals in our study believed that the system enabled increased efficiency in care 
and that it could save resources. As Piette et $\mathrm{al}^{37}$ have pointed out, mHealth program should be based on the patient's unique and changing needs. In the context of our study, this means that the need for a reorganization of care regarding clinic visits and the continuous responsibility of professionals to engage in patient-reported data must be addressed as a way of safeguarding the interest in use and adoption. ${ }^{19}$ Continuous adjustment and translation of generic systems to local practices are also of importance for adoption. ${ }^{38}$

Thus, the challenges detected in our study involve a detailed repertoire of both organizational and technological issues. ${ }^{11}$ Regarding the latter type of challenge, both patients and professionals mentioned aspects more closely related to their use of the system and its qualities concerning, for example, the visualization of the graphs and the option to tailor the system to personal needs. If this challenge is addressed, the users do not have to "put up with" deficits in system design but will perceive that it becomes easier to use over time due to a customization to user needs and increased usability. ${ }^{19}$ A no less important technological challenge is the need to handle the experienced need to align the system into the current and future technological infrastructure in health care. Despite the seemingly "lightness" of a mobile phonebased system, this does not mean that it can be seen as viable for a more loosely coupled connection to infrastructure, as argued in a recent research. ${ }^{39}$ Instead, adoption in regular care would be easier if the system became part of a standard infrastructure presented in national mHealth innovation programs in, for example, primary care.

\section{Strengths and limitations of the study}

A particular strength of this study was its inclusion of both patient and professional views, as previous qualitative studies have tended to focus on only one of the involved parties. By studying the two groups at the same time, with similar questions, we bring both stakeholders' perspectives on experiences, expectations and challenges. In this manner, we see how patient and professional users perceive the system in clinical practice - the detailed experiences of which are decisive, we argue, for taking relevant action in further development to create sustainable engagement with users ${ }^{19}$ in order to accomplish adoption and actual use. The design, validation of items and evaluation of the system were done in close cooperation with the patients and professionals. The interactive mobile phone-based system used is robust and not dependent on the technical platform. The patients could use their own mobile phone (with platforms such as Java Micro Edition, iOS, Android and Windows Phone).
There are a number of limitations to the study. The participants were mainly well-educated and of Swedish origin, why sample bias in relation to lack of cultural diversity in the sample needs to be considered. A further limitation may be that only the most interested, adherent patients with a habit of using their mobile phone and eager to improve their health participated in this study. Another challenge may be that older people have difficulties to use new technology. It has, however, recently been reported that the elderly in Sweden are frequent users of the Internet. In the year of 2017, the first time a majority (56\%) of the oldest age group, 76 years or older, used the Internet. ${ }^{40}$ The development of mobile phones with larger screens and buttons facilitates the use of mobile phones for elderly with visual and manual difficulties. The developed system has shown support for patients to become autonomous and take on extended responsibility for their health. ${ }^{41}$

\section{Implications for clinical practice and future research}

The results provide a rich account of opportunities based on actual user experiences, but we argue that the challenges and problematic aspects are of even more importance in further research, as well as on the path to accomplishing adoption. Through this valuable user input, ${ }^{19}$ we can see that details in the design and functionality of the visualization and features for interacting with the system in practical use must be addressed as a first step but, through insights from professionals, that changes are needed in order to align it to the technical infrastructure in health care. In fact, changes related to, for example, visualization and technical infrastructure will be part of an emergent further step in our research program. However, adoption in general, ${ }^{11}$ as well as with the specific intention to accomplish the partnership between patients and professionals in person-centered care in particular, comprises organizational aspects that in this study involve the interaction between home and clinical environments. To improve chronic illness care, Kawi ${ }^{6}$ pointed out that self-management support needs systematic implementation, evaluation and research in order to guide health care providers, clinics and organizations in future development. Our research emphasizes the important aspect of the alliance between patients and professionals, as well as issues related to responsibilities and time spent on activities to measure and verify the results herein. It is not the technology itself that makes this difference, but how the system is put to use - adopted - and how relevantly the system as a whole responds to the patient communication of BP, symptoms and well-being. In this 
manner, the system may have an important role to play in person-centered care.

The study has been performed in authentic clinical practice. In Sweden, physicians and nurses are working together on the follow-up of patients with hypertension. The premises for the consultation of the interactive mobile phone-based system were completely new regardless of profession. The potential differences between physicians and nurses in relation to patient consultations might be of interest, but not a focus of this analysis. However, it might be a topic of interest for further research.

\section{Conclusion}

For the development of a sustainable and person-centered support system to be adopted in daily life, it is important to study the mundane, practice-based aspects of how patients and professionals use and evaluate new technology. An adjustment of the organization of care and an extension of the educational role of professionals to fully benefit the technology would facilitate adoption in clinical practice. Adoption would also be enabled by the potential to integrate the system into the general technical infrastructure. Taking increased responsibility as a patient, by understanding factors affecting one's well-being, was reported in this study as an enabling factor for a more effective care. Documentation and visualization of patients' self-reports and the possibilities to communicate these with professionals may be a significant resource for person-centered care.

\section{Acknowledgments}

The authors are grateful to the patients and health care professionals for their contributions to this research. The research reported here has been financed by and conducted within the University of Gothenburg LETStudio, in collaboration with the University of Gothenburg Centre for Person-Centred Care (GPCC) in Sweden. The LETStudio, a strategic initiative for promoting interdisciplinary research within the Learning Sciences at the University of Gothenburg, addresses issues of knowledge, learning, communication and expertise in the contemporary society. The GPCC is funded by the Swedish Government's grant for Strategic Research Areas, Care Sciences (Application to Swedish Research Council number 2009-1088) and co-funded by the University of Gothenburg, Sweden.

\section{Disclosure}

The authors report no conflicts of interest in this work.

\section{References}

1. Go AS, Mozaffarian D, Roger VL, et al. Heart disease and stroke statistics - 2014 update: a report from the American Heart Association. Circulation. 2014;129(3):e28-e292.

2. Chobanian AV. Time to reassess blood-pressure goals. $N$ Engl J Med. 2015;373(22):2093-2095

3. Mills KT, Bundy JD, Kelly TN, et al. Global disparities of hypertension prevalence and control: a systematic analysis of population-based studies from 90 countries. Circulation. 2016;134(6):441-450.

4. Barlow J, Wright C, Sheasby J, Turner A, Hainsworth J. Self-management approaches for people with chronic conditions: a review. Patient Educ Couns. 2002;48(2):177-187.

5. Petitti DB, Grumbach K. Variation in physicians' recommendations about revisit interval for three common conditions. J Fam Pract. 1993; 37(3):235-240.

6. Kawi J. Self-management support in chronic illness care: a concept analysis. Res Theory Nurs Pract. 2012;26(2):108-125.

7. Dwarswaard J, Bakker EJM, van Staa A, Boeije HR. Self-management support from the perspective of patients with a chronic condition: a thematic synthesis of qualitative studies. Health Expect. 2016;19(2): 194-208.

8. Ekman I, Swedberg K, Taft C, et al. Person-centered care - ready for prime time. Eur J Cardiovasc Nurs. 2011;10(4):248-251.

9. Jolles EP, Clark AM, Braam B. Getting the message across: opportunities and obstacles in effective communication in hypertension care. J Hypertens. 2012;30(8):1500-1510.

10. Chandak A, Joshi A. Self-management of hypertension using technology enabled interventions in primary care settings. Technol Health Care. 2015;23(2):119-128.

11. Cresswell KM, Worth A, Sheikh A. Integration of a nationally procured electronic health record system into user work practices. BMC Med Inform Decis Mak. 2012;12:15.

12. Carruthers SG. Assimilating new therapeutic interventions into clinical practice: how does hypertension compare with other therapeutic areas? Am Heart J. 1999;138(3 suppl):S256-S260.

13. Langenau E, Kachur E, Horber D. Web-based objective structured clinical examination with remote standardized patients and Skype: resident experience. Patient Educ Couns. 2014;96(1):55-62.

14. Ketikidis P, Dimitrovski T, Lazuras L, Bath PA. Acceptance of health information technology in health professionals: an application of the revised technology acceptance model. Health Informatics J. 2012; 18(2):124-134.

15. Rosas LG, Trujillo C, Camacho J, Madrigal D, Bradman A, Eskenazi B. Acceptability of health information technology aimed at environmental health education in a prenatal clinic. Patient Educ Couns. 2014;97(2): 244-247.

16. Mulvaney SA, Rothman RL, Osborn CY, Lybarger C, Dietrich MS, Wallston KA. Self-management problem solving for adolescents with type 1 diabetes: intervention processes associated with an Internet program. Patient Educ Couns. 2011;85(2):140-142.

17. Antheunis ML, Tates K, Nieboer TE. Patients' and health professionals' use of social media in health care: motives, barriers and expectations. Patient Educ Couns. 2013;92(3):426-431.

18. Bengtsson U, Kasperowski D, Ring L, Kjellgren K. Developing an interactive mobile phone self-report system for self-management of hypertension. Part 1: patient and professional perspectives. Blood Press. 2014;23:288-295.

19. Cresswell KM, Lee L, Mozaffar H, Williams R, Sheikh A, NIHR ePrescribing Programme Team. Sustained user engagement in health information technology: the long road from implementation to system optimization of computerized physician order entry and clinical decision support systems for prescribing in hospitals in England. Health Serv Res. 2017;52(5):1928-1957.

20. Hallberg I, Taft C, Ranerup A, et al. Phases in development of an interactive mobile phone-based system to support self-management of hypertension. Integr Blood Press Control. 2014;7:19-28. 
21. Hallberg I, Ranerup A, Kjellgren K. Supporting the self-management of hypertension: patients' experiences of using a mobile phone-based system. J Hum Hypertens. 2016;30(2):141-146.

22. Bengtsson U, Kjellgren K, Hofer S, Taft C, Ring L. Developing an interactive mobile phone self-report system for self-management of hypertension. Part 2: content validity and usability. Blood Press. 2014;23: 296-306.

23. Ranerup A, Hallberg I. Actors and intentions in the development process of a mobile phone platform for self-management of hypertension. Inform Health Soc Care. Epub 2014 Jun 24:1-20.

24. Bengtsson U, Kjellgren K, Hallberg I, Lindwall M, Taft C. Improved blood pressure control using an interactive mobile phone support system. J Clin Hypertens (Greenwich). 2016;18(2):101-108.

25. Parati G, Stergiou GS, Asmar R, et al. European Society of Hypertension Practice Guidelines for home blood pressure monitoring. J Hum Hypertens. 2010;24(12):779-785.

26. O’Brien E, Atkins N, Stergiou G, Karpettas N, Parati G, Asmar R. European Society of Hypertension International Protocol revision 2010 for the validation of blood pressure measuring devices in adults. Blood Press Monit. 2010;15:23-38.

27. Braun V, Clarke V. Using thematic analysis in psychology. Qual Res Psychol. 2006;3:77-101.

28. World Medical Association. World Medical Association Declaration of Helsinki: ethical principles for medical research involving human subjects. JAMA. 2013;310(20):2191-2194.

29. Schwartz CL, McManus RJ. What is the evidence base for diagnosing hypertension and for subsequent blood pressure treatment targets in the prevention of cardiovascular disease? BMC Med. 2015;13(1):1-9.

30. van de Bovenkamp HM, Dwarswaard J. The complexity of shaping self-management in daily practice. Health Expect. 2017;20(5): 952-960.

31. Sharon T. Self-Tracking for Health and the Quantified Self: Re-Articulating Autonomy, Solidarity, and Authenticity in an Age of Personalized Healthcare. Philosophy \& Technology. 2017;30(1):93-121.
32. Kjellgren KI, Svensson S, Ahlner J, Säljö R. Antihypertensive treatment and patient autonomy - the follow-up appointment as a resource for care. Patient Educ Couns. 2000;40(1):39-49.

33. Fletcher BR, Hinton L, Hartmann-Boyce J, Roberts NW, Bobrovitz N, McManus RJ. Self-monitoring blood pressure in hypertension, patient and provider perspectives: a systematic review and thematic synthesis. Patient Educ Couns. 2016;99(2):210-219.

34. Jankowska-Polańska B, Uchmanowicz I, Dudek K, Mazur G. Relationship between patients' knowledge and medication adherence among patients with hypertension. Patient Prefer Adherence. 2016;10:2437-2447.

35. Lupton D. Quantifying the body: monitoring and measuring health in the age of mHealth technologies. Crit Public Health. 2013;23(4): 393-403.

36. Flynn SJ, Ameling JM, Hill-Briggs F, et al. Facilitators and barriers to hypertension self-management in urban African Americans: perspectives of patients and family members. Patient Prefer Adherence. 2013;7: 741-749.

37. Piette JD, List J, Rana GK, Townsend W, Striplin D, Heisler M. Mobile health devices as tools for worldwide cardiovascular risk reduction and disease management. Circulation. 2015;132(21):2012-2027.

38. Silsand L, Ellingsen G. Generification by translation: designing generic systems in context of the local. J Assoc Inf Syst. 2014;15(4):177-196.

39. Bygstad B. Generative innovation: a comparison of lightweight and heavyweight IT. J Inform Technol. 2017;32(2):180-193.

40. Nordicom [webpage on the Internet]. The Swedes and the Internet 2017. 2017. Available from: http://www.nordicom.gu.se/en/latest/news/ swedes-and-internet-2017. Accessed January 23, 2018.

41. Bengtsson U, Kjellgren K, Hallberg I, Lundin M, Mäkitalo Å. Patient contributions during primary care consultations for hypertension after self-reporting via a mobile phone self-management support system. Scand J Prim Health Care. 2018;36(1):70-79.

42. 21 Century Mobile, Stockholm Sweden. Available from: www. cqmobil.se and from August 2018. www.21st.se. Accessed March 08, 2018 .
Patient Preference and Adherence

\section{Publish your work in this journal}

Patient Preference and Adherence is an international, peer-reviewed, open access journal that focuses on the growing importance of patient preference and adherence throughout the therapeutic continuum. Patient satisfaction, acceptability, quality of life, compliance, persistence and their role in developing new therapeutic modalities and compounds to optimize

\section{Dovepress}

clinical outcomes for existing disease states are major areas of interest for the journal. This journal has been accepted for indexing on PubMed Central. The manuscript management system is completely online and includes a very quick and fair peer-review system, which is all easy to use. Visit http://www. dovepress.com/testimonials.php to read real quotes from published authors. 